Plenary Session 2-Legal

\title{
26 DOES LAW HAVE A ROLE TO PLAY IN ADVANCE CARE PLANNING?
}

B P White ${ }^{1}{ }^{1}$ Health Law Research Centre, Faculty of Law, Queensland University of Technology, Queensland, Australia

10.1136/bmjspcare-2013-000491.26

Background The role of law in end of life care is vexed. Legal risk (or perceptions of it) can impede good end of life care through defensive medicine, and legal processes can be slow to respond to clinical need. Some also argue that legal considerations are not part of clinical decisionmaking at the end of life. Yet an integral part of the regulatory framework on which advance care planning is based is at least partly sourced in law.

Aim To consider how law can support advance care planning and end of life care.

Discussion Although there are clear limits on what law can achieve, there are good reasons to co-opt law into advance care planning in a deliberate and structured way. Principled reasons include that law is a reflection of community values. More pragmatic considerations include that the involvement of law cannot be avoided as part of advance care planning and end of life care.

Conclusion If a role for law is inevitable in advance care planning and end of life care, we should acknowledge this and grapple with it squarely. This requires end of life policies to include legal considerations and accurately represent them, and for clinicians to be 
supported to know and navigate the law. Where law fails to support good end of life care, this should be addressed directly and the law reformed. Ongoing dialogue between health and legal professionals to achieve this is needed. 